\title{
Research on Model Innovation of Ideological and Political Education in Colleges under the Network Environment
}

\author{
Rongling Hu ${ }^{1}$ \\ ${ }^{1}$ Wuchang Shouyi University, Wuhan Hubei, 430064
}

Keywords: Model Innovation, Ideological and Political Education, Network Environment

\begin{abstract}
The rapid development of network technology has provided opportunities and challenges of ideological and political education and broke the original content and methods of education. The network has enriched the content, broadened the knowledge and shared more integrated information. Visualization teaching, personalized education and advanced way to interact are presented, which are good for innovation in ideological and political education. On the other hand, bad information and foreign culture and politics are difficult to control and filter. It is necessary to improve the network supervision with network technologies. Most important model innovation are constructing featured websites such as red sites, guiding the right direction with socialist core values, using regionalization of socialist core values such as 'Wuhan good man' to reinforce ideological education, and using online platform to develop online moral education.
\end{abstract}

\section{Introduction}

With the rapid development of information technology, the Internet, as an information platform and communication tool, has been widely used in various fields such as socio-political, economic and scientific education and culture. It has provided new human interaction space and development conditions and formed a brand-new Web environment. The college students in universities and colleges are the groups that have the largest number of people who have a high degree of network access. Network activities are an important part of their after-school life and are changing their lifestyles. In the process of using the Internet, college students become information receivers and disseminators, and they also become shapers and shapers of ideas. Therefore, the rise of the Internet not only provide opportunities for development, but also raise challenges for the network of ideological and political education in universities; it not only change the guiding mode of traditional public opinion and the occupation of ideological and cultural positions, but also provide a new perspective for network ideological and political education in Colleges. Faced with the new requirement of strengthening and improving college students' ideological and political education, college ideological and political educators must grasp the influence of the network environment on the formation of college students' ideology and morality, and create a good education environment; they must innovate the ways and methods of ideological and political education in universities and continue to expand. The space for ideological and political education on the Internet will enhance the effectiveness of ideological and political education activities under the network environment. It is necessary to improve the scientific level of ideological and political education in Colleges and strive to create a new situation in the practice of network ideological and political education [1].

\section{Opportunities and Challenges of Ideological and Political Education Innovation in Colleges under Network Environment}

At this time, we are in a network environment. Because of the continuous development of high technology, the Internet has entered our lives and learning, and it has become an important channel for us to obtain information. Therefore, ideological and political education in universities will also sprout in the network environment. Through the rapid dissemination of information networks, our ideological and political education has also been continuously innovated, benefiting university students. 
The ideological and political education under the network environment has enriched the content of education and broadened the educational space. Under the platform of the Internet, the ideological and political education we receive is not merely the result of the spread of individual thoughts compared with the traditional ones, but is the integration of different ideas from multiple perspectives and fields, which is conducive to broaden the scope of knowledge. The timeliness of information makes the information we accept the most novel, most targeted, and most informative, such as current affairs politics, major deeds, etc. New types of ideological and political education are free from the limitations of the past; With space limitations, as long as the computer is used as a platform, it can communicate with many countries, view various documents and read the books that you want to read, thus broaden your knowledge and allow college students to enter a large space for information sharing [2].

The innovation of ideological and political education in Colleges in the network environment has achieved the pertinence and timeliness of education. Under traditional ideological and political education, the information received by students is single, and the problems encountered cannot be resolved in time. Teachers and students cannot well communicated, and education in the network environment can be one-on-one and provide a platform for teachers and students to communicate. When problems are encountered, they can be answered in multiple ways to correctly guide the students' values. In the process of ideological and political education in Colleges, full use of network technology, the use of advanced media teaching, vividly communicate knowledge to students, inspire students' proactive learning attitude, and improve the level of ideological and political education in Colleges.

The rapid development of network technology has greatly helped the ideological and political education in universities and improved our traditional education model. However, everything has its two sides. The network not only gives us opportunities but also gives us corresponding challenges. The openness and equality of the Internet cater to the public's tastes, and it is in line with people's values. As a result, its amount of information is too large. Therefore, it is difficult to control and filter. There will be some bad information and foreign culture, economy, and politics will also occur. The point of view invades our lives as a result of the positive communication and realization of ideological and political education in Colleges. Therefore, while browsing the Internet to broaden the knowledge of ideological and political education, we should take the best of it and go to the dross to improve the effectiveness of the ideological and political education innovation curriculum under the network environment [3].

\section{Model Breakthrough in Innovation in Ideological and Political Education in Colleges}

Visualization teaching means that the teaching content is visually presented. The important role of big data is also the visual analysis of the data. Some ideas and preferences of students are presented in the form of charts and data, and the valuable information is classified into categories. Therefore, the teaching is more targeted, and it is necessary to grasp the direction in the guidance of students' thoughts, and to express the ideological and political education in Colleges in a way that is more loved by students. Taking Marxist theory as an example, the chapter theory of contradictory dialectics is more abstract, and it is generally accepted that there is no need to pay attention to this part in high school. At this time, using the analysis of big data, we can see how students are interested in and understanding of this aspect. After teachers visually analyze the data, they can also directly use these visual data as teaching materials.

The data analysis focuses on each subtle part of the education process and analyzes the position that this part occupies in the whole. For education, the pursuit of personalized education for each student individual as far as possible is always the pursuit of education. Big data analysis makes this pursuit possible. Understanding the distribution of students' ideological characteristics can fully grasp the characteristics of students and provide targeted teaching so that the outlook on life and world outlook promoted in ideological and political education in universities can truly help college students.

The decrease of interaction of classroom education is a problem that university classrooms can 
hardly avoid. This is especially true in the "less important subjects" of ideological and political education in Colleges. In response to this, Big Data conducts timely processing and analysis of students' thoughts and behaviors, and determines the content of future courses through student feedback. The establishment of an effective and lasting big data system is conducive to timely feedback on students' classroom responses. We can foresee that in the near future, we will use a more advanced way to interact in the classroom. Like the current variety shows, students hold voting and opinion terminals in their hands so that they can truly exchange ideas and speak freely in the classroom. In the near future, this teaching mode can be realized through the mobile phone APP. Its significance is very significant and it will be a milestone for university education in the Internet age.

\section{Improve the Network Supervision System and Realize its Mechanism Innovation}

Strengthening the monitoring and management of the Internet is an important way to realize the ideological and political education in Colleges in the Internet era. The first is to strengthen administrative management and improve the monitoring organization. Universities should not only establish a comprehensive educating mechanism for teaching and educating people, but also focus on mobilizing and coordinating social, student, and family factors to jointly maintain the security of network information, and explore the establishment of communication between schools, students, and families. Mechanism to realize the socialization of network ideological and political education. Colleges should combine school monitoring with government supervision, internal and external monitoring of the school campus network, formulate monitoring standards, specify the monitoring scope, increase the monitoring and filtering of information on the Internet; accelerate the improvement of the network public opinion crisis management system, and change the way of managing public opinions. Blocking sparseness, through the establishment of a sound, timely, transparent, and impartial information release mechanism, purifying the information access channels of college students, and guiding the right direction of public opinion. The second is the use of network technologies to continuously innovate information prediction and feedback mechanisms for ideological and political work in universities, and to filter, eliminate, block, and block bad information; through the establishment of a national-level "information customs", the international Internet portal is closely monitored and tested. The information that enters our country is strictly filtered to create a good learning environment for college students. Third, the government and the school through the sound laws and regulations, the development of network behavior guidelines and related network management regulations, to popularize the legal knowledge of college students, to strengthen the legal awareness of college students, information awareness, and regulate their network behavior.

First, the construction of featured websites, college ideological and political education websites should give full play to their educating functions, have the characteristics of clear themes, rich content, and entertaining, so we must constantly innovate the content of ideological and political education political websites, and strengthen ideological and political education means,such as the red culture contains rich revolutionary spirit and historical and cultural connotations. Strengthening the construction of red themes in the campus network can provide ideological and political educators with a variety of pedagogic forms to better play the function of ideological and political education. At present, many Colleges in China have their own campus networks, such as Tsinghua University's "Red Site” and Nankai University's awareness network. The establishment of a red site is a new frontier for ideological and political education in Colleges, and guides the correct network. Public opinion plays an important role.

The second is guiding the right direction with socialist core values, using regionalization of socialist core values such as 'Wuhan good man' to reinforce ideological education. In Wuhan city, there are many places of historic interest such as Yu Gongji where the story of Dayu's flood control has been handed down. showing the students around and opening up Wuhan traditional culture websites in the universities of Wuhan to guide students love their hometown and motherland, inherit the fine traditon. 
Third, to use the Internet exchange platform to improve the effectiveness of ideological and political education. The construction of ideological and political education websites should adhere to the student-centered concept, make full use of the interactivity and openness of the network, and realize the combination of education and service. Educators can use the BBS exchange platform, we-chat, we-bo to encourage students to participate in the discussion of major events and issues, express their opinions, publish mainstream opinions through authority, and grasp the power of online opinion and initiative; at the same time, they can also use online platforms to develop online moral education. Online party building activities, online psychological counseling, online employment guidance services, and the establishment of a network of ideological and political education theory course websites have attracted students to actively participate in online ideological and political education, thereby broadening the channels and channels for educating people and enhancing the ideological and political education.

\section{Conclusion}

The network environment has provided ideological and political education in Colleges with abundant ideological work content, and expanded the space and channels for ideological and political education. Ideological and political educators can not only strengthen their sense of innovation, but also change their concepts and roles in time, study new situations, and explore new ideas. Only by solving new problems and new conflicts can we maintain the vitality of ideological and political education and effectively bring into play the functions of ideological and political education.

\section{Acknowledgements}

Fund Project: Special Project for Humanities and Social Sciences of the Ministry of Education in 2017: Research on the Regionalization of Socialist Core Values in Colleges, 17JD710077

\section{References}

[1] Ding Hong. Internet's Influence on Ideological and Political Work in Colleges [J]. College Theoretical Front, 2017, (6): 37-38.

[2] Su Zhenfang. Ideological and political work in the Internet age [J]. Journal of Fujian Normal University, 2017, (1): 36-37.

[3] Su Zhenfang. Ideological and political education [M]. Beijing: Social Sciences Academic Press, 2006:333-340.

[4] Tang Yueming. The application of virtual reality technology in education [M]. Beijing: Science Press, 2007: 77.

[5] Tian Weiyi. Several thoughts on strengthening college students' online ideological and political education [J]. College Theoretical Front, 2018, (11): 17-19. 